\title{
The Influx of Ph.D.s into Librarianship: Intrusion or Transfusion?
}

In a survey of seventy-two university libraries and forty-four library schools, the entry of subject Ph.D.s into librarianship during the past three years was measured and evaluated. It was discovered that the number of subject Ph.D.s enrolling in library schools is increasing rapidly, that job opportunities for subject Ph.D.s in librarianship are very good, and that subject Ph.D.s are generally employed in choice positions.

F EW ACADEMiC LibraRians or faculty members in library schools would doubt that the profession is being infused at an increasing rate by persons who hold a Ph.D. or another terminal degree in a subject field other than library science. Two decades ago Phyllis Richmond observed that subject Ph.D.s enter the field of librarianship for two reasons: (1) their interest in libraries developed from teaching or research in their subject field, or (2) they enter by design perhaps because they do not want to teach. ${ }^{1}$ Today we can add a third reason -the academic job crisis!

It is obvious that the influx into librarianship of subject Ph.D.s is being accelerated by the strained job market in many academic disciplines. Persons who have recently received a terminal degree and even those who once felt secure in their teaching positions are finding themselves thrown into the wolfish employer's market in which there are often hundreds of applicants

Rush G. Miller is director of library services, W. B. Roberts Library, Delta State University, Cleveland, Mississippi. for every opening. Opportunities for displaced or unemployed academics are extremely narrow, and many have moved into libraries as a last ditch effort to remain in academia.

The result of the influx of subject Ph.D.s has been to spark discussion among librarians and library educators concerning the desirability of allowing these "subject specialists" to "seek cover" in librarianship. It has also led to a challenge by at least one "convert," W. A. Moffett, who wrote that the academic job crisis provides librarianship with an opportunity to recruit highly capable librarians from the ranks of new Ph.D.s as well as out-of-work experienced scholars. Moffett cites several shortcomings on the part of library schools and libraries in failing to take advantage of this opportunity afforded by the job crisis. ${ }^{2}$

The question of whether or not libraries should employ subject Ph.D.s is hardly a new issue. Controversy over the subject $\mathrm{Ph} . \mathrm{D}$. in libraries dates from the development of the first Ph.D. program in library science at the University of Chicago in 1928. Most librarians dis- 
agreed when Dean Louis Wilson wrote in the first issue of College \& Research Libraries that the doctorate in library science was preferable to the subject degree for librarians. ${ }^{3}$ In the same issue, C. C. Williamson, Sydney B. Mitchell, Carl M. White, Robert J. Kerner, and Nathan Van Patten expressed the opinion that the subject doctorate was the proper training for academic librarians. ${ }^{4}$ Nathan Van Patten went so far as to state: "It seems clear to me that it is much better to attempt to make a librarian from a man or woman who is already well established in the practice of one of the older recognized professions." ${ }^{5}$ Robert Downs added his name to the list of supporters of subject Ph.D.s in 1946. Downs also stated that library school faculties should be composed of subject specialists. $^{6}$

During the decades from 1930 to 1960 , subject $\mathrm{Ph} . \mathrm{D}$. degrees were emphasized by librarians as the most appropriate terminal degree. The library literature of that period dealing with this issue culminated in 1957 with the publication of an article by Phyllis Richmond. The article, entitled "The Subject Ph.D. and Librarianship," provided insight into the job opportunities for subject Ph.D.s in libraries. ${ }^{7}$ However she failed to mention the field of library education in this regard. Her conclusion that a subject Ph.D. would have the best of both worlds (status with faculty members as well as with other librarians) was an accurate reflection of the prestige enjoyed by those subject Ph.D.s who entered the field of librarianship in those decades.

Since 1960 the major emphasis in librarianship in regard to terminal degrees has been on the Ph.D. degree in library science. The development of library science as a full-fledged "profession" has meant divorcing it from subject areas and a redefinition in terms of information science. Today there are approximately twenty library schools which offer the Ph.D. degree, and this number will surely continue to increase in the future. However, since the number of $\mathrm{Ph}$.D.s granted by them is relatively few, subject Ph.D.s continue to fill the gaps in administration and teaching.

A major study of the opinions of library science Ph.D.s was conducted by Ray and Patricia Carpenter and published in the Journal of Education for Librarianship in $1970 .^{8}$ It showed that despite the emphasis on that degree, most persons holding a Ph.D. in library science consider the prestige of the degree to be very low in relation to other fields. The Carpenters' study also implied that subject Ph.D.s have encouraging job prospects in library school teaching since 41 percent of the library science Ph.D.s surveyed believed that subject doctors should be represented on library school faculties "in strength," and another 25 percent felt that they should constitute at least half of such faculties. Their conclusion was that there are not nearly enough Ph.D.s in library science to meet the demand and that, therefore, subject Ph.D.s will continue to be utilized.

Despite the encouragement of the Carpenter study for subject Ph.D.s in librarianship, the situation in 1976 is far different from that in 1970 if only that there are many more subject Ph.D.s searching for job opportunities in libraries. Some questions remain unanswered. This study attempts to fill in a few of the gaps in our knowledge of this situation. It attempts to assess the present extent to which subject Ph.D.s are employed in librarianship, to gauge the influx of subject Ph.D.s into library schools, to compare the attitudes of educators with those of librarians in regard to this phenomenon, and to discover practical opportunities and limitations in libraries for subject Ph.D.s. In short, is the influx of subject Ph.D.s an 
unwanted intrusion or a needed transfusion of fresh talent?

\section{THE STUDY}

With the aid of a research grant from the University of Mississippi, the author was able to survey ninety-two large university libraries between December 17, 1974, and February 1, 1975. This population consisted of all American university libraries in the Association of Research Libraries as well as the members of the Association of Southeastern Research Libraries which do not belong to ARL. In addition to libraries, all American Library Association accredited library schools were surveyed with a separate questionnaire. Replies were received from seventy-two libraries and forty-four library schools. This represents a return rate of 78 percent for libraries and 80 percent for library schools. Since these research libraries would probably employ a larger number and percentage of subject specialists than smaller college and university libraries, the results are not meant to be applied universally.

One major purpose of this study was to determine the number of subject Ph.D.s either currently employed in the field or enrolled in library schools. Library directors were asked to give the number of Ph.D.s currently employed in professional positions in their libraries, the number of subject Ph.D.s employed, and the number of subject Ph.D.s with a master's degree in library science employed. Deans of library schools were asked to give current enrollment figures (fall 1974) for the master's degree program, the number of students with a subject Ph.D. degree, and the number of master's degrees awarded to Ph.D.s during the previous two years (1972-73, 1973-74).

A surprisingly large number of subject $\mathrm{Ph}$.D.s were employed in the seventy-two libraries responding to the questionnaire (Table 1). The total number of subject Ph.D.s was 175 out of a total number of 207 Ph.D.s employed. In other words, 84.5 percent of all Ph.D.s who held professional positions in these libraries were subject Ph.D.s. Of the subject Ph.D.s employed in these libraries, 106 or 60.6 percent had some library science training.

\section{TABLE 1}

Current Number of Subject Ph.D.s EMPLOYED IN 72 LIBRARIES AS OF February 1, 1975

Total number of Ph.D.s employed

Total number with subject Ph.D.

Percentage of Ph.D.s with subject degree 84.5 Total number of subject Ph.D.s with

M.L.S.

Percentage of subject Ph.D.s with M.L.S. 60.6

In the fall 1974 the forty-four accredited library schools which responded to the questionnaire had enrolled a total of 9,224 master's degree students (Table 2). Of this number 125 held the Ph.D. degree. Only twelve library schools or 27.3 percent of those responding had no Ph.D.s enrolled, and 72.7 percent had at least one Ph.D. The number of subject Ph.D.s enrolled in master's degree programs may not seem excessively large since they constitute only 1.4 percent of the total student bodies; but when compared with the figures given for the past two years, a marked increase is readily apparent. For the previous two years there were a total of $101 \mathrm{Ph} . \mathrm{D} . \mathrm{s}$ enrolled in these fortyfour schools. Although no figures are available by year for comparison, an average figure of 50.5 per year is assumed. Since the figures for the current year include only the fall quarter (or semester), the total number of subject Ph.D.s in these programs for the entire year should be larger than 125 . Disregarding this fact, the average number of subject Ph.D.s enrolled in these library schools has risen in two years from an average of 1.2 per school to 2.7 per school. 
TABLE 2

Subject Ph.D.s Enrolled in 44 Accredrted LiBRARY SCHOOLS

Total enrollments in master's program

Number with subject Ph.D.

9,224

Percentage with subject Ph.D.

Average number/library school

Average number/library school during past 2 years

Total number with subject Ph.D. during past 2 years

Another indication of the extent of the influx of subject Ph.D.s into library schools was gained from a question which asked deans to indicate whether the number of Ph.D.s entering librarianship is increasing markedly, increasing somewhat, stable, or decreasing. A majority ( 55.9 percent) of the deans stated that the number was increasing somewhat, and only 18.9 percent felt that the number was increasing markedly. Yet the enrollment figures for the past three years seem to indicate a marked increase overall. One respondent who had no subject Ph.D.s currently enrolled but who had interviewed several prospective students who held Ph.D.s remarked: "I am beginning to wonder if the real deluge is now about to hit us."

\section{Placement of Subject Ph.D.s}

Another important consideration concerning subject Ph.D.s in librarianship is the specific areas within the library in which they are employed most often. In other words, in which particular positions are subject Ph.D.s considered desirable by administrators? Library directors were asked to give the number of subject Ph.D.s employed in the areas of administration, archives/special collections, subject bibliography, reference, and technical services. Not surprisingly, the largest number of subject Ph.D.s (52) were employed in archives and special collections. Large numbers were also employed in administration (39) and subject bibliography (44). Reference and technical services accounted for thirty-four Ph.D.s altogether with six employed as branch librarians.

Library school deans were also asked for information concerning the areas of employment in which subject Ph.D.s were placed upon completion of the master's degree during the past two years. The same five basic categories were included as possibilities with the addition of library education. However, deans were not asked to give the number placed in each of the categories since the information would not be readily available. Of the thirty-two library schools which have placed subject Ph.D.s during the past two years, 48.4 percent have placed at least one Ph.D. in the area of reference, 45.2 percent have placed Ph.D.s in subject bibliography, and 29 percent have placed people in administrative positions, while an equal percentage have teaching positions.

The questionnaires were designed not only to elicit factual information concerning the employment of subject Ph.D.s in libraries but also to discover the attitudes of both library school deans and library directors concerning the areas of librarianship in which subject Ph.D.s could best be utilized. Both groups were asked to mark those areas for which subject Ph.D.s should be considered; and this question was designed to find out if there is substantial agreement between deans and administrators concerning the desirability of hiring subject Ph.D.s in various areas (Table $3)$.

The deans of library schools tended to be more optimistic about the types of positions in which a subject Ph.D. might be employed than were the library directors. Of the thirty-four deans who responded to this question, 74.2 percent felt that subject Ph.D.s should be employed in administrative positions in academic libraries. On the other hand, only 50 percent of the directors felt that a subject Ph.D. would 
TABLE 3

Attrtudes of Library Directors and Deans Concerning Desirability of Hiring Ph.D.s in Various Positions

\begin{tabular}{lcccccc}
\hline \hline & $\begin{array}{c}\text { Administration } \\
\%\end{array}$ & $\begin{array}{c}\text { Library } \\
\text { Education } \\
\%\end{array}$ & $\begin{array}{c}\text { Reference } \\
\%\end{array}$ & $\begin{array}{c}\text { Bibliography } \\
\%\end{array}$ & $\begin{array}{c}\text { Archives } \\
\%\end{array}$ & $\begin{array}{c}\text { Technical } \\
\text { Services } \\
\%\end{array}$ \\
\hline $\begin{array}{l}\text { Library Directors } \\
(\mathrm{N}=72)\end{array}$ & 50 & $\mathrm{NA}$ & 70.8 & 87.5 & 86.1 & 34.7 \\
$\begin{array}{l}\text { Library School } \\
\text { Deans }(\mathrm{N}=34)\end{array}$ & 74.2 & 67.7 & 83.9 & 93.6 & 87.1 & 3.2 \\
\hline
\end{tabular}

enhance a person's qualifications for such a position. Likewise, a larger proportion of library school deans felt that subject Ph.D.s should be employed in reference and bibliography than did directors. At the "lower end" of the spectrum, a much larger percentage of library directors than deans felt that a subject Ph.D. would be an asset in technical services.

In order to assess further the opinions of administrators of both libraries and library schools concerning job opportunities in librarianship for subject Ph.D.s, each group was asked to categorize the job possibilities for subject Ph.D.s as either excellent, very good, fair, or poor (Table 4). Although library school deans tend to be optimistic in terms of the beginning level of employment for subject Ph.D.s, as seen in Table 3 , library directors are more optimistic concerning the overall job opportunities for subject Ph.D.s in the field. Almost 20 percent of the library administrators rated the opportunities for subject Ph.D.s as excellent, while only 2.6 percent of the library school deans agreed. The largest proportion of both groups felt that the opportunities were very good, while sizable percentages felt that the subject $\mathrm{Ph}$.D. has only a fair chance to find suitable employment in library science.

\section{Salaries for Subject Ph.D.s}

Important factors in regard to the job opportunities in librarianship for subject Ph.D.s are the amount and nature of the experience required. Library school deans were surveyed as to the salary levels of the graduates as well as their opinions concerning the level at which a subject Ph.D. with an M.L.S. should begin. Of the thirty-nine deans who responded to this question, 71 percent stated that the subject Ph.D.s placed by them had no previous library experience. Despite this fact 60.7 percent received positions with advanced salaries. When asked at which salary level, advanced or beginning, a subject Ph.D. with an M.L.S. should begin, 63.2 percent felt that such a person should begin at an advanced position while only 13.2 percent felt he should begin on the same level with other master's students. The remainder believed that a subject Ph.D. could be hired at either level depending upon such factors as his or her competence, experience, or the position for which the candidate was being considered.

Library directors were also asked their opinion concerning the salary level at which a subject Ph.D. should be hired as well as whether or not they would hire a Ph.D. with no previous library experience. The opinions of sixty-eight library directors proved to be rather ambiguous. When asked if they would hire a subject Ph.D. with no library experience for an advanced salaried position, 42.7 percent stated that they would and 45.6 percent stated they would not. The remaining respondents qualified their answer as to the position or the individual or both. However, when asked what the beginning level of the subject Ph.D. 
TABLE 4

AsSESSMENT OF Overall Job OpPortunities for SUbJect Ph.D.s IN Librarianship

\begin{tabular}{lrrrrrrrrrr}
\hline \hline & \multicolumn{2}{c}{ Excellent } & \multicolumn{2}{c}{ Very Good } & \multicolumn{2}{c}{ Fair } & \multicolumn{3}{c}{ Poor } & \multicolumn{3}{c}{ Depends } \\
& No. & \multicolumn{1}{c}{$\%$} & \multicolumn{1}{c}{ No. } & $\%$ & No. & $\%$ & No. & $\%$ & \multicolumn{1}{c}{ No. } & $\%$ \\
\hline Library Directors $(\mathrm{N}=68)$ & 13 & 19.1 & 31 & 45.6 & 19 & 27.9 & 5 & 7.4 & 0 & 0 \\
Library School Deans $(\mathrm{N}=38)$ & 1 & 2.6 & 20 & 52.6 & 14 & 36.9 & 2 & 5.3 & 1 & 2.6 \\
\hline
\end{tabular}

with an M.L.S. would be in relation to a person with the M.L.S. only, 64.7 percent stated that they would hire the $\mathrm{Ph} . \mathrm{D}$. at a higher level and only 26.5 percent at the same level.

Clearly the person with a Ph.D. degree commands a higher salary than a person with a M.L.S. only. But experience is also an important factor to library directors. An average of 2.6 years of experience would be required by those who stated that they would not hire a subject Ph.D. for an advanced salary.

\section{SubJect BACKGround}

Library directors strongly rejected the notions that either academic preparation (graduate study for the Ph.D.) or prior teaching experience are equivalent to library experience in determining salary levels. Only 22.4 percent stated that they would allow academic preparation to be considered library experience while 68.6 percent would not; and the remaining 9 percent would also consider the type of position. Directors were even more opposed to previous teaching experience influencing salary levels in the library. Fully 76.1 percent were opposed to this concept; while 16.4 percent favored it; and 7.5 percent approved it with conditions.

One interesting characteristic of the subject Ph.D.s in librarianship was the dispersement of subject fields represented by their degrees. The questionnaire sent to library schools listed the fields of history, English, education, and law with space for others to be written in. Of those Ph.D.s enrolled in master's degree programs during the past two years, 16.9 percent held degrees in history and a like amount in English; 9.6 percent were from education; 7.2 percent were from languages; 4.8 percent were from law; and 3.6 percent came from music. The remainder held subject Ph.D.s in fields ranging from biochemistry and biology to political science and theology. Although the fields in the humanities and social sciences, hardest hit by the current job crisis, also represented the highest percentages of Ph.D.s entering librarianship, there appears to be an influx of subject specialists from a wide range of areas.

\section{EDUCATION FOR LIBRARIANSHIP}

Another important factor in assessing the job opportunities in librarianship for subject Ph.D.s is the area of education for librarianship. Ray and Patricia Carpenter have pointed out in a study of attitudes of library science Ph.D.s that not only is there a shortage of persons with the Ph.D. in library science to fill faculty positions in library schools, but a vast majority of library science faculty members with the Ph.D. in library science feel that library schools should include on their faculties subject doctorates "in strength." 9 In the library schools surveyed and responding to the present survey, 41.8 percent of the faculty members held subject Ph.D. degrees. When asked if it would be necessary for a subject Ph.D. to have practical library experience to be considered for a faculty position, 69.2 percent replied yes and 30.8 percent replied no. The surprising figure is the number of 
library schools which would not require practical library experience for persons holding the terminal degree in a subject field for positions on their staffs. At least one dean of a large university library school indicated that he had recently hired a subject Ph.D. with no practical experience, although he would have preferred experience. This seems to bear out the Carpenters' conclusion concerning the lack of experienced doctorates for faculty positions.

One of the reasons for the possibilities of teaching in library schools for subject Ph.D.s is the small number of $\mathrm{Ph} . \mathrm{D}$. degrees awarded in library science annually. Of the thirteen schools replying which give Ph.D. degrees, only 113 degrees were awarded for the past two years. Of this number thirty-one did not seek employment. Of the eighty-two who did seek positions in librarianship, 43.9 percent went into library administration. Only forty-six of the Ph.D.s from these schools were employed in teaching positions.

\section{ConClusion}

The primary result of this survey was to confirm the beliefs of many in the profession that a sizable influx of subject Ph.D.s is occurring. It would appear that the number of subject Ph.D.s enrolled in library schools has at least doubled during the past year.

At the present time job opportunities in libraries for subject Ph.D.s appear to be very good despite the current job pinch in librarianship. When asked which degree, subject $\mathrm{Ph} . \mathrm{D}$. or library science Ph.D., they would prefer for positions in their libraries, directors invariably chose the subject Ph.D. over the library science Ph.D. or stated that it would depend on the type of position. Not one director surveyed would automatically prefer a library science Ph.D. One director summed up his feelings by stating:

There are positions for which a library school Ph.D. would be preferred to a subject Ph.D., but generally speaking, I believe the subject Ph.D. preferable for most university library positions.

The majority of library directors would hire a subject Ph.D. at a salary level somewhat higher than a person without a terminal degree but not at what they would define as an advanced position (one requiring some library experience).

On the other hand, despite the apparently favorable market for subject Ph.D.s in university libraries, there has been little encouragement for Ph.D.s to enter library school. Although 88 percent of library school deans responding to this survey stated that an influx of subject Ph.D.s would not be detrimental to the profession, not one actively recruited subject Ph.D.s and several were openly hostile to the idea. The dean of the University of Michigan library school in his "Report to the Alumni" for 1974 dealt with this problem and correctly pointed out the frustrations and roadblocks a subject Ph.D. can expect in a library position. He pointed out the fact that library directors or other librarians may resent the degree. However, he failed to point out that many library school faculty members, especially those without terminal degrees, present an equally frustrating problem. The net result of this announcement is to discourage subject Ph.D.s even though it is intended only to let them know the difficulties ahead.

It is discouraging to note that not one responding library school dean could point to a single special program of study designed to utilize the specialties of the subject Ph.D. ${ }^{10}$ Library school deans are overlooking entirely several areas of possible employment for subject Ph.D.s. If librarianship is to respond to Moffett's challenge, programs must be designed in such areas as archives and special collections, law librarianship, and subject bibliography 
beyond the basic courses taken by all students. For example, librarians have been content to hire archivists and special collections librarians who have no background in library science or only a degree in library science and no background in history. Degree programs should be developed in library schools to attract persons with Ph.D.s in appropriate areas of history so that they can be given an appreciation of the library and its functions. At the present time there are no degree programs for archivists, and the library schools should not abdicate this important opportunity. Certainly, special programs of study can be developed for other subject specialties as well. The broad diversity of subject Ph.D.s enrolled in library schools reflects not only the tight job market in academic circles, but also the opportunities and possibilities in the library profession for persons within a varied range of special talents.

The number of subject Ph.D.s seeking positions in the field of librarianship is increasing rapidly and will continue to increase into the foreseeable future. How the profession reacts to this fact will determine whether these subject Ph.D.s will provide a transfusion of specialized talents which will be beneficial to the profession or "pseudo professionals" who will be unable to adapt their specialties to library situations. Should the latter occur, the influx of subject Ph.D.s will be an unwelcome and detrimental intrusion.

\section{REFERENCES}

1. Phyllis Allen Richmond, "The Subject Ph.D. and Librarianship," College \& Research Libraries 18:123-26, 146 (March 1957).

2. W. A. Moffett, "The Academic Job Crisis: A Unique Opportunity, or Business as Usual?" College \& Research Libraries 34:19194 (May 1973).

3. Louis R. Wilson, "Essentials in the Training of University Librarians-I," College \& Research Libraries 1:13-21 (Dec. 1939).

4. Sydney B. Mitchell, "Essentials in the Training of University Librarians-II"; C. C. Williamson, "Essentials in the Training of University Librarians-III"; Robert J. Kerner, "Essentials in the Training of University Librarians-IV"; Carl M. White, "Discussion," College \& Research Libraries 1:22-38 (Dec. 1939).

5. Nathan Van Patten, "Discussion," College \& Research Libraries 1:34 (Dec. 1939).
6. Robert B. Downs, "Preparation of Specialists for University Libraries," Special $\mathrm{Li}$ braries 37:212-13 (1946).

7. Richmond, "The Subject Ph.D.," p.123-26, 146.

8. Ray Carpenter and Patricia Carpenter, "The Doctorate in Librarianship and an Assessment of Graduate Library Education," Journal of Education for Librarianship 11:3-45 (Summer 1970).

9. Ibid., p. 35 .

10. Information received at a later date from the Graduate Library School, University of Chicago, called attention to the Council on Library Resources grant for postdoctoral fellowships for holders of the Ph.D. in fields other than librarianship for work toward the M.A. degree in librarianship at the University of Chicago. College $\& R e$ search Libraries News 35:6 (Jan. 1974). 


\section{New Books}

Astrophysics and Space Science Library

53. The Solar Chromosphere and Corona

Quiet Sun

by R. Grant Athay
1976, xil +504 pp. Cloth Dfl. 150, - /US $\$ 59.00$

55. Solid State Astrophysics

Proceedings of a Symposium on Solld State Astrophyaics heid at the University College, Cardith, July 1974

edited by Nalin Chandra Wickramasinghe and D. J. Morgan
$1976, x i i+302$ pp. Cloth Dfl. 95,- / US $\$ 37.00$

57. The Scientific Satellite Programme during the International Magnetospheric Study Proceedings of the 10th ESLAB Symposium held at Vienna, Austria, 10-13 June 1975

edited by $\mathrm{K}$. Knott and B. Battrick

1976. $x y+464$ PP. Cloth Dfl. 110,- / US $\$ 39.50$

Boston Studies in the Philosophy of Science

18. Philosophical Problems of Modern Physics by Peter Mittelstaedt 1976, ix $+207 \mathrm{pp}$. Cloth On. $50,-$ I US $\$ 18.50$

27. Topics in the Philosophy of Biology edited by Marjorie Grene and Everett Mendelsohn 1976 , xiil $+454 \mathrm{pp}$. Cloth Dit. 110,- I US \$39.50

33. Science and its Public: The Changing Relationship edited by Gerald Holton and William Blanpied $1976, \mathrm{xxy}+288 \mathrm{pp}$. Cloth Dff. 70,-1 US $\$ 26.00$

43. Language in Focus: Foundations, Methods and Systems edited by Asa Kasher
$1976,679 \mathrm{pp}$. Cloth Df., 165,- 1 US $\$ 64.00$ Paper Dil. 85,- I US $\$ 29.00$

\section{Geophysics and Astrophysics Monographs}

\section{Solar Flares}

by Zdenek Svestika
$1976 . x v+273$ pp.

Paper Dfl. 60,-1 US \$23.00

Homogeneous Catalysis in Organic and Inorganic Chemistry

1. Homogeneous Hydrogenation in Organic Chemistry

by F. J. McQuillin
1976 , vili $+133 \mathrm{pP}$ Cloth Dfl. 50,-1 US\$19.50

International Studies Series in Economics and Econometrics

8. Economic Planning Studies; Ragnar Frisch's Memorial Essays

A Nobel Prite in Economica Contribution

edited by Frank Long

Cloth Dfl. 58,-/US $\$ 19.50$

The Jerusalem Symposia on Quantum

Chemistry and Biochemistry

8. Environmental Effects on Molecular Structure and Properties

edited by Bernard Pullman

edited by Bernard Pulliman
$1976, x i+588 \mathrm{pp}$. Cloth Ofl. 195,- / US $\$ 75.00$
Mathematical Physics and Applied Mathematics

1. Quantum Mechanics, Determinism, Causality, and Particles

An International Collection of Contributions in Honour of Loule de Broplie on the Occasion of the Jubliee of his Colebrated Theais

edited by M. Flato, Z. Maric, A. Milojevic, D. Sternheimer and

Cloth Dfl. $80,-1$ Us $\$ 29.00$

NATO Advanced Study Institutes Series C. Mathematical and Physical Sciences

23. Renormalization Theory

edited by $G$. Velo and A.S. Wiphtm

1976. vii + 482 pp. Cloth Dfl. 110-1 US $\$ 39.50$

25. Electrode Processes in Solid State lonics edited by M. Kleitz and J. Dupury

1976 , xiv $+466 \mathrm{pp}$. Cloth DH. 100,- / US $\$ 39.50$

26. Long-Time Predictions in Dynamics edited by V. Szebehely and B, D. Tapley
$\begin{array}{ll}1976, x v+358 \text { pp. } & \text { Cloth Dfl. } 85,-1 \text { us } \$ 33.00\end{array}$

\section{Sovietica}

36. Marxism and Religion in Eastern Europe Papers presented at the Banft International Slavic Conference, September 4-7, 1974 edited by Richard T. De George and James P. Scanian $1976, x v i+181 \mathrm{pp}$. Cloth Dit. 70,-i US $\$ 27.00$

\section{Synthese Library}

72. Essays on Explanation and Understanding Studies in the Foundations of Humanities and Sociel Sciences edited by Juha Manninen and Aaimo Tuomela
1976 , vii + 440 pp.

78. Logic and Probability in Quantum Mechanics edited by Patrick Suppes Cloth Dfl. 110,- / US \$39.50
1976, xii + 521 pp.

81. Can Theories be Refuted? Easays on the Duhem-Quine Theais edited by Sandra G. Harding 1976. xxi + 318 pp. Cloth Dfl. 110,- / US \$39.50 Paper Dil. $48,-$ IUS $\$ 18.00$

93. Local Induction edited by Radu J. Bogdan 1976, xiv + $340 \mathrm{pp}$. Cloth Dfl. 110,- / US $\$ 39.50$

94. Understanding and Prediction Easays in the Methodology of Social and Behavioral Sciences by Stefan Nowak $\quad$ Cloth Dfl. 150,- / US $\$ 60$

\section{Vienna Circle Collection}

3. Ernst Mach: Knowledge and Error Sketches on the Paychology of Enquin Erkenntnis und Irrtum, L 1976. xxoxyii + 393 pP. Cioth Dfl. 135, - / US $\$ 52.00$ Paper DIt. 75,-

\section{Western Ontario Series}

6. Foundations of Probability Theory, Statistical Inference and Statistical Theories of Science Proceedings of an Internation edited by W. L. Harper and C. A. Hooker

1976, xoxvi +1004 pp. Cloth Dfl. 280,-rus $\$ 105.00$ Paper Dit. 150- luss 80.00

All Reidel series are available on continuation order

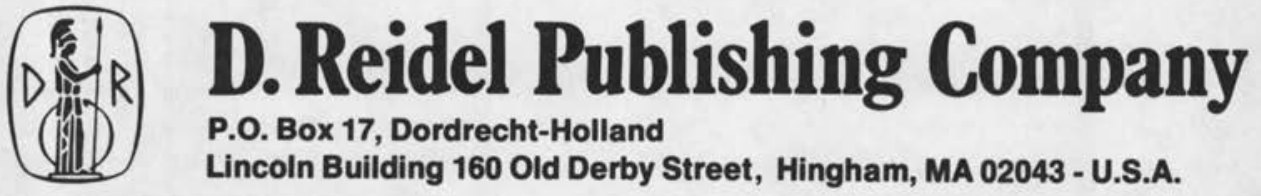

